\title{
Invasive aspergillosis in solid organ transplant patients: diagnosis, prophylaxis, treatment, and assessment of response
}

\author{
Dionysios Neofytos $^{{ }^{*}}$ (D), Carolina Garcia-Vidal ${ }^{2}$, Frédéric Lamoth ${ }^{3,4}$, Christoph Lichtenstern ${ }^{5}$, Alessandro Perrella ${ }^{6,7}$ and \\ Jörg Janne Vehreschild $8,9,10$
}

\begin{abstract}
Background: Invasive aspergillosis (IA) is a rare complication in solid organ transplant (SOT) recipients. Although IA has significant implications on graft and patient survival, data on diagnosis and management of this infection in SOT recipients are still limited.

Methods: Discussion of current practices and limitations in the diagnosis, prophylaxis, and treatment of IA and proposal of means of assessing treatment response in SOT recipients.

Results: Liver, lung, heart or kidney transplant recipients have common as well as different risk factors to the development of IA, thus each category needs a separate evaluation. Diagnosis of IA in SOT recipients requires a high degree of awareness, because established diagnostic tools may not provide the same sensitivity and specificity observed in the neutropenic population. IA treatment relies primarily on mold-active triazoles, but potential interactions with immunosuppressants and other concomitant therapies need special attention.

Conclusions: Criteria to assess response have not been sufficiently evaluated in the SOT population and CT lesion dynamics, and serologic markers may be influenced by the underlying disease and type and severity of immunosuppression. There is a need for well-orchestrated efforts to study IA diagnosis and management in SOT recipients and to develop comprehensive guidelines for this population.
\end{abstract}

Keywords: Aspergillus, Invasive pulmonary aspergillosis, Microbiome, Mucorales, Mucormycosis, Solid organ transplantation

\section{Background}

Invasive mold infections (IMI), in particular invasive aspergillosis (IA), are a relatively rare complication in solid organ transplant (SOT) recipients [1-3], albeit associated with high rates of graft loss and mortality [4]. The overall incidence of IA among SOT recipients remains below 10\% and varies depending on the organ transplanted $[1,5]$. IA post-SOT is associated with high overall mortality, with 3-

\footnotetext{
* Correspondence: Dionysios.Neofytos@hcuge.ch

${ }^{1}$ Service des Maladies Infectieuses, Hôpitaux Universitaires de Genève, Rue Gabrielle-Perret-Gentil 4, Geneva, Switzerland

Full list of author information is available at the end of the article
}

month rates as high as $15-25 \%$ in non-liver and up to 80 $90 \%$ in liver SOT recipients (Table 1) $[1,2]$.

Considering the devastating consequences of IA in SOT recipients $[3,5]$, mold-active primary prophylaxis is used routinely in some transplant centers [10]. However, the administration of broad-spectrum antifungal prophylaxis in the SOT setting remains controversial, considering the lack of available evidence, significant drug-drug interactions (particularly between azoles and some immunosuppressive agents), costs, selection for resistant pathogens (in particular, Candida spp.) and the risk of breakthrough IMI caused by resistant molds [11]. Attempts to stratify antifungal prophylaxis based on

(c) The Author(s). 2021 Open Access This article is licensed under a Creative Commons Attribution 4.0 International License, which permits use, sharing, adaptation, distribution and reproduction in any medium or format, as long as you give appropriate credit to the original author(s) and the source, provide a link to the Creative Commons licence, and indicate if changes were made. The images or other third party material in this article are included in the article's Creative Commons licence, unless indicated otherwise in a credit line to the material. If material is not included in the article's Creative Commons licence and your intended use is not permitted by statutory regulation or exceeds the permitted use, you will need to obtain permission directly from the copyright holder. To view a copy of this licence, visit http://creativecommons.org/licenses/by/4.0/ The Creative Commons Public Domain Dedication waiver (http://creativecommons.org/publicdomain/zero/1.0/) applies to the data made available in this article, unless otherwise stated in a credit line to the data. 
Table 1 Epidemiology of invasive aspergillosis in SOT recipients. The large variations of the overall mortality rates in heart and kidney recipients can be explained by the corresponding variations in follow-up in the different studies (3-months $[1,3,5]$ or 12-months [6, 7])

\begin{tabular}{llll}
\hline Population & Incidence (\%) & Overall mortality (\%) & References \\
\hline Heart & $3.5-26.7$ & $36-66.7$ & {$[1,3,5,8,9]$} \\
Kidney & $1.2-4$ & $4-25$ & {$[1,3,5]$} \\
Liver & $1-4.7$ & $83-88$ & {$[1,3,5]$} \\
Lung & $8.3-23.3$ & 4.2 & {$[1,3,5]$} \\
\hline
\end{tabular}

identification of IA predictors have largely failed [12]. In addition, although the pathophysiology of IA and the effects of the intensity and duration of immunosuppressive therapy on IA are now better appreciated [5], a large array of additional risk factors appear to be of variable importance for different transplanted organs (Table 2).

Here we briefly discuss current practices and limitations in the diagnosis, prophylaxis, and treatment of IA, as well as means of assessing treatment response in SOT recipients.

\section{Methods}

This consensus document was the product of an expert panel based on a consensus, decision-making process to produce an unbiased, independent and high-quality manuscript. Participants were chosen on the basis of their expertise in the field of medical mycology and transplantation medicine. Each expert was assigned to one of the following topics: epidemiology, diagnosis, radiological and clinical presentation, treatment and clinical outcomes of IA in SOT recipients. Literature review was performed through the PubMed database for articles written in English between 2000 and 2018 on IA-epidemiology, IAdiagnosis, IA-treatment, and IA-clinical outcomes in SOT. All participants reviewed individually the available literature on the topic they were assigned to and chose the most relevant data to present and discuss. Critical discussion of all data was subsequently performed by all experts and consensus decisions were made on each topic. Agreement by all members of the panel was required for a recommendation to be made and included in the consensus document. Each author provided a draft manuscript on their assigned topic. The final manuscript was reviewed and accepted as such by all authors. The organization plan used is provided in Fig. 1.

\section{Results \\ Diagnostic workup}

The diagnosis of IA relies on a multitiered approach that should consider risk factors and the local epidemiology, as well as the performance and limitations of the available diagnostic tools $[14,15]$. IA diagnosis warrants a comprehensive and rigorous workup, including a combination of histopathology, microbiology, serology, and imaging data in the relevant clinical setting. However, these considerations are predominately based on data generated from patients with hematologic malignancies and hematopoietic cell transplantation (HCT) recipients. Based on the limited data available on diagnostic tools in SOT recipients, imaging and biomarkers, such as the galactomannan enzyme immunoassay (GM EIA), appear to perform less optimally compared to neutropenic patients [1, 2, 4, 27]. Lack of prospective high-quality clinical studies on the performance of imaging, microbiology, and/or laboratory biomarkers for the diagnosis of IA in SOT recipients significantly limits our ability to establish a definitive diagnosis of IA in SOT setting and requires additional efforts to optimize the use of these tools. The work done by the International Society for Heart and Lung Transplantation (ISHLT) for lung and heart transplant recipients [28] should be expanded to all other forms of transplantation.

\section{Microbiology}

Traditional diagnostic approaches include staining with Gomori's methenamine silver or periodic acid-Schiff (PAS) stains and fungal cultures of clinical specimens, with a historical sensitivity that varies between 20 and $70 \%$ [15, 29-35]. Sensitivity and positive predictive

Table 2 Risk factors for invasive aspergillosis in SOT recipients. Herbrecht et al. [13] have listed the general risk factors for invasive fungal infections in haemato-oncological patients and solid organ transplant recipients, but the list is continuously increasing, and presently includes a number of additional factors [14-16], among them influenza, [17, 18]

\begin{tabular}{|c|c|c|}
\hline & Risk factors & References \\
\hline Heart & $\begin{array}{l}\text { Reoperation; CMV infection; post-transplantation hemodialysis; presence of another patient with IA in the transplant program } 2 \\
\text { months before or after the procedure; rejection, admission to the ICU, mechanical ventilation, and extracorporeal membrane } \\
\text { oxygenation (ECMO) }\end{array}$ & {$[19,20]$} \\
\hline Kidney & $\begin{array}{l}\text { Bloodstream infections; pre-transplant chronic pulmonary obstructive disease; impaired graft function; long-term dialysis prior } \\
\text { to transplantation; serious post-transplant infections }\end{array}$ & {$[21,22]$} \\
\hline Liver & $\begin{array}{l}\text { MELD score, choledochojejunostomy; anastomosis; bacterial infections in the first month and absence of antifungal prophylaxis; } \\
\text { cytomegalovirus (CMV) reactivation; renal failure; hemodialysis; re-transplantation or transplantation for fulminant hepatic failure; } \\
\text { reoperation }\end{array}$ & $\begin{array}{l}{[5,12,22-} \\
24]\end{array}$ \\
\hline Lung & $\begin{array}{l}\text { Single lung transplantation; pre- and post-transplant colonization with Aspergillus spp., early airway ischemia, CMV infection, } \\
\text { rejection }\end{array}$ & {$[25,26]$} \\
\hline
\end{tabular}




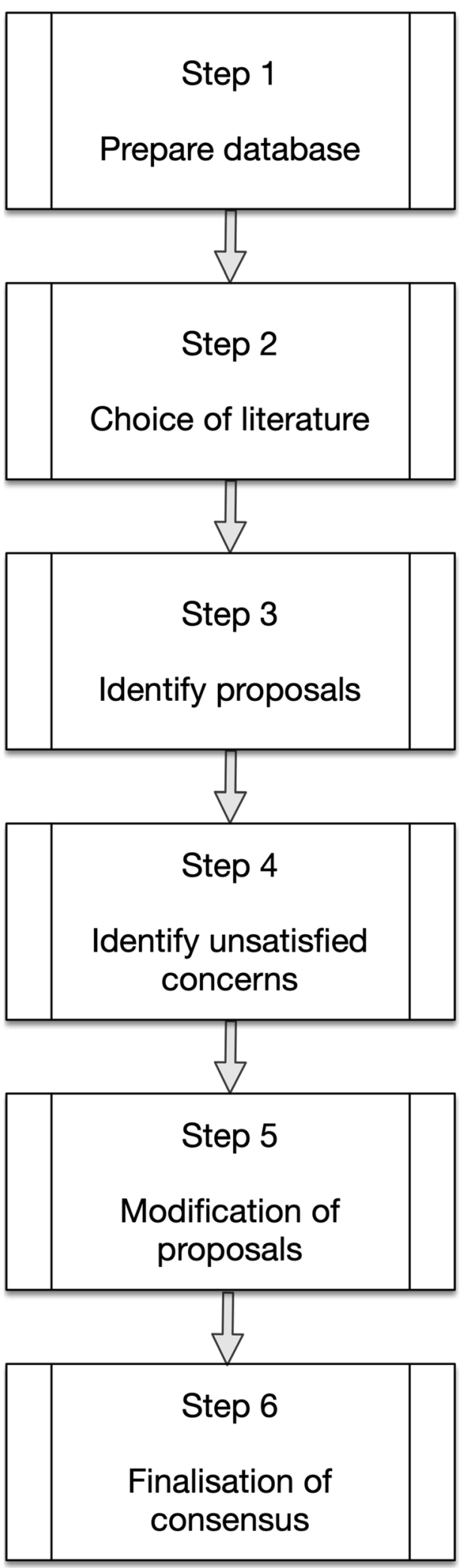

Fig. 1 Basic steps to consensus decision making used in this work values heavily depend on the quality of the specimen obtained (sputum versus bronchoalveolar lavage, BAL), severity of disease, and organism inoculum [15, 34, 36-38].

To fill in the gap, additional non-culture methods have been introduced in clinical practice, including fungal biomarkers, such as the GM EIA and beta-D-glucan (BDG), and molecular testing with polymerase chain reaction (PCR). Among the available biomarkers and despite its established role in hematologic patients [39], the GM EIA performs rather poorly in serum samples of SOT recipients, with a sensitivity ranging from 30 to $58 \%[1,27,40-42]$. In contrast, the performance of GM EIA in BAL of SOT recipients appears to be better, with a sensitivity in the range of $67-100 \%$ [5]. The BDG test remains of relatively poor value, due to its lack of specificity for Aspergillus spp. [43-49] and limited sensitivity particularly in liver transplant recipients, ranging between 58 and 65\% [42, 43, 50]. Although currently not widely used, Aspergillus specific PCR in the serum or BAL has been shown to offer additional diagnostic value in both neutropenic and non-neutropenic patients [5153]. However, the validation of new diagnostic tests for the diagnosis of IA in SOT recipients remains problematic, due to the lack of easily applicable gold standards and the constantly decreasing rates of biopsy performance in clinical practice.

Notably, the worldwide shift towards establishing a diagnosis of IA using fungal biomarkers and without isolating the pathogen may pose significant problems in the management of IA in the near future. Fungal pathogen availability is important for antifungal susceptibility testing, a crucial step to optimize the management of patients with IA. This is even more pertinent now, as there have been increasing reports of worldwide emergence of multi-triazole resistance among Aspergillus fumigatus, in most cases due to a TR34/L98H mutation [54-56], and intrinsically resistant, cryptic species in the Aspergillus fumigatus complex, such as $A$. lentulus, A. udagawae, and $A$. viridinutans, are emerging as important pathogens in this universal antifungal prophylaxis era $[57,58]$. A. calidoustus exhibits some levels of intrinsic azole resistance and has also been reported as an emerging cause of IA in non-neutropenic transplant patients receiving azole prophylaxis $[11,59]$, whereas $A$. terreus is intrinsically resistant to amphotericin B [60]. Several molecular protocols are available to reliably identify and characterise azole-resistant Aspergillus isolates [61-63], including at least a commercial kit $[63,64]$. Recently a specific TaqMan Real-Time PCR has been shown to detect triazole-resistant strains of $A$. fumigatus even in the presence of only a low percentage of resistant cells [65]. In any case, antifungal susceptibility testing (AST), either by conventional in vitro AST $[66,67]$, or new methods 
such as MALDI-TOF mass spectrometry assays [68], is of critical value for the treatment of such patients and should be performed regularly in patients with IMI when a pathogen is identified, at least in regions with known resistance problems, as recommended also by the ESCM ID-ECMM-ERS guideline [15].

\section{Other diagnostic laboratory tools}

The lateral-flow device (LFD) [69] applied to BAL has been shown to provide a reliable diagnosis of IA [70]. The technique has a short turnaround time, is easy to use and cost effective [71]. When combined with a quantitative PCR, it has contributed to detect invasive pulmonary aspergillosis in immunocompromised patients [72] and its performance was superior to that of the GM EIA test in SOT recipients [73]. The LFD, however, appears to have a reduced sensitivity in the presence of antifungal treatment [74], and, contrary to the GM test, provides only qualitative data [75]. In addition, to our knowledge, only one validated commercial kit is available [71].

\section{Inflammatory markers}

Non-specific inflammatory markers, such as the Creactive protein (CRP) or fibrinogen, and proinflammatory markers, such as cytokines and procalcitonin (PCT), have so far not been evaluated in SOT recipients for the diagnosis of IA. In neutropenic patients with IA, high initial interleukin (IL)-8 and continuously elevated IL-6, IL-8, and CRP levels during treatment have been shown to be early predictors of therapeutic failure, suggesting that cytokine and CRP profiles could be helpful to identify non-responders, guiding to targeted, early changes in antifungal treatment [76]. The assessment of other host biomarkers, such as haptoglobin $(\mathrm{Hp})$ and annexin A1 [77] or cytokines such as serum IL-10, and interferon- $\gamma$ [76], needs further evaluation $[78,79]$. None of these markers, however, are sufficiently specific to play a role in the IA diagnosis in this population.

\section{Imaging}

Computerised tomography $(\mathrm{CT})$ is an important tool to diagnose IA [14, 15]. The appearance of CT findings in SOT recipients with IA may not always be similar to that observed in neutropenic patients, as the classic halo sign, air-crescent sign and well-defined nodular lesions seem to be less frequent $[80,81]$. Conversely, nonspecific radiologic manifestations, including consolidations, pleural effusions, and ground-glass opacities, have often been described in SOT recipients with invasive pulmonary aspergillosis [82]. Some of these findings were not included in the revised European Organisation for Research and Treatment of Cancer - Mycoses Study Group (EORTC-MSG) definition consensus guidelines for the diagnosis of IA [83] and have now been partly included in the updated criteria for the diagnosis of invasive fungal infections (IFI) by the EORTC-MSG group [84]; they have been used, however, in modified diagnostic criteria among SOT recipients in observational retrospective studies [1, 85]. Lack of validation of these findings may pose additional problems in the conduction of clinical trials, particularly with regards to the accuracy and homogeneity of IA diagnosis in these settings. However, the existing body of literature and accumulating clinical experience call for collaborative action to improve our understanding of CT findings indicative of IA in SOT recipients. In the meantime, suspicious pulmonary lesions of unknown origin should prompt a rigorous workup, including bronchoscopy and/or biopsy. Recent research has suggested the potential utility of CT pulmonary angiography, using vessel occlusion signs as specific indicator of IA in hematology patients [86-88], but this strategy has not yet been evaluated in the SOT population.

\section{Treatment}

Limited treatment options for SOT recipients with IA are available (Table 3). This is, in part, due to the complicated profile of SOT recipients, who comprise a wide array of underlying pathologies (from kidney to liver to lung transplant recipients) and underlying organ dysfunctions. Furthermore, in SOT recipients, specific pharmacokinetic/pharmacodynamic (PK/PD) and drug-drug interaction considerations significantly impact antifungal treatment options [91-94]. The distinct toxicity profiles of different antifungal drugs adds to therapeutic complexity in the setting [95]. Potential liver toxicity associated with triazoles may create additional problems in liver transplant recipients [96], whereas the nephrotoxicity associated with conventional but also with the lipid formulations of amphotericin B limits the utility of these agents in kidney transplant recipients and patients with pre-existing renal failure due to other reasons, including administration of calcineurin inhibitors [97]. Coadministration of triazoles, particularly voriconazole and posaconazole, with the most common immunosuppressive agents in SOT recipients, such as tacrolimus and sirolimus, is another major concern because of potential important drug-drug interactions [98].

Voriconazole is the first-line option of IA therapy based on international guidelines [14, 25]. The use of voriconazole in SOT recipients, however, may be hindered due to potential drug-drug interactions, predominately with concomitantly administered immunosuppressive agents, including cyclosporine, tacrolimus and sirolimus [99-103]. Rigorous therapeutic drug monitoring (TDM) of these drugs is warranted to avoid potentially severe toxicities from overdosing [14, 15, 104, 105]. In addition, the use of 
Table 3 Primary antifungal treatment options for the treatment of IA and special considerations in solid organ transplant recipients

\begin{tabular}{|c|c|c|c|c|c|c|}
\hline Agent & Dose & Recommendation & $\begin{array}{l}\text { Potential Adverse } \\
\text { Events }\end{array}$ & $\begin{array}{l}\text { Potential Drug } \\
\text { Interactions }\end{array}$ & $\begin{array}{l}\text { Additional } \\
\text { Considerations }\end{array}$ & Monitoring \\
\hline Voriconazole & $\begin{array}{l}\text { Induction: } 6 \mathrm{mg} / \mathrm{kg} \mathrm{IV}^{\mathrm{a}} \\
\text { every } 12 \mathrm{~h} \text { the first day } \\
\text { Maintenance: } 4 \mathrm{mg} / \mathrm{kg} \mathrm{IV}^{\mathrm{a}} \text {, } \\
\text { 200-300 } \mathrm{mg} \text { PO twice } \\
\text { daily }\end{array}$ & 1st line [14] & $\begin{array}{l}\text {-Hepatotoxicity } \\
\text {-Visual changes } \\
\text {-Neurologic } \\
\text { toxicity } \\
\text {-Rash and } \\
\text { photosensitivity } \\
\text {-Periostitis } \\
\text {-QTc } \\
\text { prolongationc }\end{array}$ & $\begin{array}{l}\text {-Sirolimus }^{d} \\
\text {-Tacrolimus }^{d} \\
\text {-Cyclosporine }\end{array}$ & $\begin{array}{l}\text {-Non-linear } \\
\text { pharmacokinetics } \\
\text {-Strong inhibitor of } \\
\text { CYP3A4 } \\
\text {-Moderate inhibitor of } \\
\text { CYP2C19 and 2C9 } \\
\text {-Metabolized via } \\
\text { CYP2C19, 2C9 and } \\
\text { 3A4 } \\
\text { - <2\% of voriconazole } \\
\text { is excreted in the } \\
\text { urine }\end{array}$ & $\begin{array}{l}\text {-Liver function tests } \\
\text {-12-lead ECG } \\
\text {-Voriconazole TDM } \\
\text {-Sirolimus, tacrolimus, } \\
\text { and cyclosporine } \\
\text { TDM }^{\mathrm{d}}\end{array}$ \\
\hline Isavuconazole & $\begin{array}{l}\text { Induction: } 200 \mathrm{mg} \text { three } \\
\text { times daily the first } 2 \\
\text { days } \\
\text { Maintenance: } 200 \mathrm{mg} \\
\text { daily }\end{array}$ & $\begin{array}{l}\text { 1st line }[15] \\
\text { Primary alternative } \\
{[14]}\end{array}$ & -Hepatotoxicity ${ }^{b}$ & $\begin{array}{l}\text {-Sirolimus } \\
\text {-Tacrolimus } \\
\text {-Cyclosporine }\end{array}$ & $\begin{array}{l}\text {-Linear } \\
\text { pharmacokinetics } \\
\text {-Moderate inhibitor of } \\
\text { CYP3A4 } \\
\text {-Metabolized via } \\
\text { CYP3A4 } \\
\text {-Isavuconazole may } \\
\text { cause QTc shortening }\end{array}$ & $\begin{array}{l}\text {-Liver function tests } \\
\text {-Sirolimus, tacrolimus, } \\
\text { and cyclosporine } \\
\text { TDM }^{\text {e }}\end{array}$ \\
\hline $\begin{array}{l}\text { Liposomal } \\
\text { Amphotericin } \\
\text { B }\end{array}$ & $3-5 \mathrm{mg} / \mathrm{kg}$ daily IV & $\begin{array}{l}\text { Primary alternative } \\
{[14,15]}\end{array}$ & - Nephrotoxicity ${ }^{9}$ & & & $\begin{array}{l}\text {-Renal function and } \\
\text { electrolytes }\end{array}$ \\
\hline \multicolumn{7}{|c|}{$\begin{array}{l}\text { IV Intravenous, PO Oral, ECG Electrocardiogram, TDM Therapeutic Drug Monitoring } \\
\text { aIV voriconazole is not recommended in patients with renal dysfunction (glomerular filtration rate }<50 \mathrm{~mL} / \mathrm{min} \text { ) due to the potential of nephrotoxicity associated } \\
\text { with the IV formulation vehicle of cyclodextrin } \\
\text { b Hepatotoxicity was significantly less frequent in patients treated with isavuconazole as compared to voriconazole in a prospective randomized clinical trial [89] } \\
\text { c Isavuconazole is associated with shortening of the QTc interval } \\
\text { dVoriconazole may significantly increase sirolimus levels, therefore close monitoring of sirolimus TDM is recommended in case of co-administration. Significant } \\
\text { dose reductions of sirolimus, tacrolimus and cyclosporine are commonly required when any of these agents is co-administered with voriconazole } \\
\text { 'Early data suggest that isavuconazole administration does not significantly affect blood concentrations of sirolimus and tacrolimus [90]. Until more data become } \\
\text { available, it is advised to closely monitor immunosuppression TDM while co-administered with isavuconazole } \\
\text { IIn cases of baseline QTc prolongation and/or co-administration with QTC prolonging agents, such as macrolides and fluroquinolones, regular QTc monitoring } \\
\text { is recommended } \\
{ }^{9} \text { Additional, noteworthy toxicities include hypomagnesaemia, renal tubular acidosis, and elevated liver function tests }\end{array}$} \\
\hline
\end{tabular}

voriconazole TDM [106, 107] is recommended to avoid off-target trough serum levels [108] and to identify treatment failure or toxicity because of inadequate drug exposure $[15,107,109]$. Despite the utility and significant benefits attained with regular TDM, voriconazole is frequently avoided in clinical practice, due to its adverse event profile, including hepatotoxicity and neurological and psychiatric symptoms, particularly early post-SOT and in liver transplant recipients.

Isavuconazole has demonstrated equal efficacy compared to voriconazole in patients with hematologic malignancies and HCT recipients [89], and is currently recommended for the treatment of IA by national and international guidelines $[14,15]$. Notably, isavuconazole has shown lower rates of liver and neurological toxicities and has fewer drug-drug interactions, including with tacrolimus and sirolimus [90]. Considering its water soluble profile, the intravenous (IV) formulation of isavuconazole does not require co-administration with cyclodextrin [110], therefore - and unlike IV voriconazole - it may be considered even in patients with borderline renal dysfunction. Despite the currently very limited relevant data, isavuconazole represents a potentially useful agent for the treatment of IA in SOT recipients, particularly early after a liver and/or kidney transplant, to avoid significant drug interactions and associated toxicities. Although not currently recommended, isavuconazole TDM may potentially inform clinical practice, considering limited data suggesting moderate interpatient variability and concentrations affected by patients' gender and weight and hemodialysis requirements $[111,112]$.

Liposomal amphotericin B ( L-AmB) monotherapy is considered second line treatment for patients with IA, but it may be used in cases when triazole administration is contraindicated due to potential drug interactions and hepatotoxicity or in the presence of azole-resistant $A s$ pergilli $[14,15]$. The role of echinocandins in the treatment of IA in SOT recipients is not clear, and the recent ESCMID-ECMM-ERS guidelines consider the use of echinocandins only as primary prophylaxis and as combination treatment for infections due to azole-resistant Aspergilli [15]. In addition, there are no convincing data that combining a broad-spectrum azole or a lipid- 
formulation of amphotericin B with an echinocandin is beneficial in the management of IA in SOT recipients, although combination antifungal therapy is prescribed in up to one third of SOT recipients with IA $[113,114]$. Combination treatment with anidulafungin and voriconazole was not associated with higher survival in high-risk hematological patients and allogeneic hematopoietic cell transplant recipients when compared with monotherapy with voriconazole, although a potential benefit was noted in post-hoc analyses of patients with a positive GM EIA optical density between 0.5 and 1.5 [115]. Based on the existing available data, combination therapy is not recommended for the treatment of IA in SOT recipients.

Posaconazole and itraconazole are included in the 2016 update of the diagnosis and management of aspergillosis by the IDSA [14, 15] but their use is limited to alternative salvage therapy. New drugs currently under development such as F901318 (olorofim) [116, 117] or ibrexafungerp (currently undergoing Phase II and III clinical trials) [118] may play a role in the management of IA, but more data are needed before further conclusions can be drawn.

\section{Antifungal prophylaxis}

Antifungal prophylaxis with posaconazole is recommended in high-risk hematological patients with profound neutropenia or with high-grade graft-versus-host-disease [14, 119], but primary antifungal prophylaxis is not routinely recommended for all SOT recipients. Furthermore, antifungal prophylactic strategies may vary significantly across different transplant centers [120-122]. In fact, based on the low incidence of IA and other IMI in the SOT population, variable timing of their occurrence post SOT, and lack of robust data to show efficacy in preventing IMI, most centers do not apply universal antifungal prophylaxis in SOT recipients. A recent prospective randomized clinical trial for antifungal prophylaxis of liver transplant recipients based on prior identified risk factors for IA failed to show significant benefit, at least partly due to the low number of patients diagnosed with IA [12]. The use of areosolized amphothericin B lipid complex as a standard mold-active prophylaxis appeared to be beneficial when used for up to 18 days after surgery [123]. A preemptive therapy is currently recommended only in lung transplant recipients, while a targeted prophylaxis is favored in liver and heart transplant recipients [25]. Overall, most existing data on prophylaxis and preemptive therapy of IA are based on retrospective cohort and case-control studies.

\section{Breakthrough fungal infections}

Breakthrough IMI with reduced susceptibility to the available antifungal agents is also a major concern that should be considered in the decision-making process of universal antifungal prophylaxis. Breakthrough IMI under mold-active prophylaxis may be caused by molds that have been selected due to intrinsic or acquired resistance to the prophylactic agent used, the latter in case of suboptimal absorption and/or tissue concentration of the administered antifungal prophylaxis [11, 124, 125]. There are few scattered data on the incidence of breakthrough IMI, with the vast majority of studies reporting, almost exclusively, on hematology patients $[119,124-$ 130]. Recently, data on breakthrough IFI in lung transplant recipients undergoing mold-active prophylaxis were reported [123]. Based on the very limited information on SOT recipients, breakthrough IMI causes vary across studies and seem to be dependent on the local epidemiological landscape and other variables. Mucorales, rare multi-drug resistant Aspergillus spp. and a shift towards rare mold species with intrinsic azole resistance compared to non-breakthrough IMI have been described as the major cause of breakthrough IMI [11, 124, 126]. Among Aspergillus spp., A. calidoustus was found to be the predominant cause of breakthrough IMI in a recent study including also SOT recipients [11]. Considering the high mortality and treatment failure rates of breakthrough IMI and the limited available therapeutic options, recent guidelines and expert reports recommend an individualized approach that considers a careful evaluation of the local epidemiology, clinical vigilance, and careful management, including empirical change of antifungal drug class [14].

\section{Monitoring response}

Until now, lack of reliable and objective follow-up markers has made clinical response assessment, even in the setting of clinical trials, a complex and cumbersome task. Consensus criteria to assess clinical response to antifungal therapy in clinical trials of IMI have already been published [131]. The most recent ESCMIDECMM-ERS guidelines on the diagnosis and management of IA propose to use a composite outcome of clinical, radiological and mycological criteria to assess IA treatment response [15]. These guidelines, however, have not been validated, are largely centered on hematological patients, and were created predominantly for use in clinical trials.

This is of relevance when considering treatment duration and response in SOT recipients with IA. Most SOT patients require life-long immunosuppression. Importantly, the level of immunosuppression, an important intervention to achieve faster and more complete control of IA, cannot be substantially reduced in most cases. These considerations may represent valid arguments for more prolonged treatment courses or secondary prophylaxis in SOT recipients. Because clinical signs of IA are scarce and non-specific, patient follow-up is primarily based on monitoring the radiological response and 
decline of serum GM EIA. Radiological response in hematological patients is notoriously delayed with an initial increase in the size of lung lesions during the first weeks despite appropriate antifungal therapy [132-136]. Data on IFI-related changes in lesion size and shape in SOT patients, in whom radiological lesions are often of different nature compared to the classical nodular lesions of hematological patients, are sparse. Until more studies provide additional insights on the evolution of radiological lesions in SOT recipients treated for IA, development of new lesions and continued increase in lesion size under treatment should alert the treating physicians for potential treatment failure and additional actions to be taken. Close follow-up of imaging findings should be performed until other clear indicators of improvement can be observed. Notably, definitive recommendations on the type and timing of clinical response in SOT recipients with IA are not currently available.

Serum GM EIA level kinetics have been reported to be good predictors of outcome of IA in hematological patients $[6,45,75,91,137,138]$, but their value in SOT recipients needs to be verified. In addition, only approximately one third of IA cases in SOT patients have positive GM EIA testing [1]. High negative predictive values of successful response to IA therapy have been reported when several biomarkers (GM EIA, panfungal quantitative PCR, and CT imaging) were combined [7]. The IDSA and ESCMID-ECMM-ERS guidelines [14, 15], however, do not provide specific advice as to which parameters and in which combination they should be used. Non-specific markers, such as CRP and cytokines have been proposed to predict treatment outcome in hematological patients [79], CRP has been described as a good independent prognostic factor in patients with acute invasive fungal rhinosinusitis [139], and its levels remained persistently elevated in non-responder leukemia patients [78]. CRP, however, is not specific for fungal infections and as SOT recipients are particularly prone to concomitant or intercurrent bacterial infections, the specificity of assessment of response to IA therapy in SOT patients based on CRP and other nonspecific inflammatory markers needs to be verified in well-designed clinical trials.

\section{Conclusions}

IA is a rare but often deadly disease in SOT recipients. Prevalence varies across transplanted organs, with lung and liver transplant patients being more often affected. Compared to neutropenic patients, diagnosis of IA in SOT recipients requires a high degree of clinical suspicion and awareness, especially because established diagnostic tools, such as the GM EIA test and CT, do not provide the same sensitivity and specificity observed in the neutropenic population.
As in other populations, IA treatment relies primarily on mold-active triazoles, but potential interactions with immunosuppressants and other concomitant therapies need special attention. High-dose corticosteroid treatment [140] and other immunosuppressive agents have been identified as significant risk factors for IA in highrisk patient categories [5, 17, 141-147]. Reduction of immunosuppression, if possible, should be considered as a part of the treatment strategy. Assessing response is already challenging in the settings of hematological and oncological patients, where clinicians typically rely on reduction of lesion size or emergence of air-crescent signs and cavities in CT scans as well as of serology (GM EIA, BDG) and inflammatory (fever and CRP) biomarkers. These criteria, however, have not been sufficiently evaluated in the SOT population and CT lesion dynamics as well as serologic markers are known to be influenced by the underlying disease as well as type and severity of immunosuppression. One major difference of SOT recipients compared to other patient groups at risk for IA is the need for life-long immunosuppression for most patients, which raises the question of optimal treatment duration and the need for secondary prophylaxis after successful treatment of an IA episode. Finally, each SOT patient category needs to be evaluated separately, because liver, lung, heart or kidney transplant recipients all have different risk factors [5, 21, 148, 149], and apparently different predispositions to the development of IA $[1,2,5]$. There is an urgent need for multicentre, international, well-orchestrated efforts on the study of IA diagnosis and management in SOT recipients to develop clear and comprehensive guidelines on the prevention, diagnosis, treatment and evaluation of therapeutic success of IA in this population.

\section{Abbreviations \\ AST: Antifungal susceptibility testing; bBDG: Beta-D-glucan; CRP: C-reactive protein ; CT: Computerised tomography; EORTC-MSG: European Organisation for Research and Treatment of Cancer - Mycoses Study Group; GM EIA: Galactomannan enzyme immunoassay; HCT: Hematopoietic cell transplantation; Hp: Haptoglobin; IA: Invasive aspergillosis; IMI: Invasive mold infections; ISHLT: International Society for Heart and Lung Transplantation; IV: Intravenous; L-AmB: Liposomal amphotericin B; LFD: Lateral-flow device; PAS: Periodic acid-Schiff; PCR: Polymerase chain reaction; PCT: Procalcitonin; PK/PD: Pharmacokinetic/pharmacodynamic; SOT: Solid organ transplant; TDM: Therapeutic drug monitoring}

\section{Acknowledgements}

This work is the outcome of an expert meeting supported by an unrestricted grant by Gilead Sciences GmbH. The help by PD Dr. Orlando Petrini, Breganzona, in preparing this manuscript is gratefully acknowledged.

\section{Authors' contributions}

All authors have contributed equally to the design, writing and preparation of the manuscript. DN designed the review and co-ordinated the project. CGV, FL, CL, AP and JJV provided scientific input for all sections. DN wrote the manuscript with input from all authors and CGV, FL, CL, AP and JJV helped in the revision of the manuscript. All authors read and approved the final manuscript. 


\section{Funding}

This review is the outcome of an expert meeting supported by Gilead GmbH for which the authors have received an honorarium and compensation for travel expenses.

\section{Availability of data and materials}

The information supporting the conclusions of this article are included within the article.

\section{Declarations}

Ethics approval and consent to participate

Not applicable.

\section{Consent for publication}

Not applicable.

\section{Competing interests}

DN has received honoraria for participating in advisory boards and acting as consultant for Gilead Science, Merck Sharp and Dohme, Pfizer, and Astellas and a grant support from Merck Sharp and Dohme.

CG-V has received honoraria for talks on behalf of Gilead Science, Merck Sharp and Dohme, Pfizer, Jannsen, Novartis, Lilly and a grant support from Gilead Science and Merck Sharp and Dohme. She has received a research grant from the Ministerio de Sanidad y Consumo, Instituto de Salud Carlos III [FIS PI18/01061] and a European Regional Development Fund (EDRD) and the INTENSIFICACIO Grant- a grant by the Catalan Health Agency [PERIS (Pla estratègic de recerca i innovació en salut - "Strategic Plan for Research and Innovation in HealthCare")]. FL has received honoraria for participating to advisory boards from MSD, Basilea and Gilead. CL has received personal fees from Merck/MSD, Gilead, Pfizer, and Astellas Pharma. AP has received honoraria for an expert meeting on behalf of Gilead Science. JJV has received personal fees from Merck/MSD, Gilead, Pfizer, Astellas Pharma, Basilea, Deutsches Zentrum für Infektionsforschung, Uniklinik Freiburg / Kongress und Kommunikation, Akademie für Infektionsmedizin, University of Manchester, Deutsche Gesellschaft für Infektiologie, Ärztekammer Nordrhein, Uniklinik Aachen, Back Bay Strategies, Deutsche Gesellschaft für Innere Medizin and grants from Merck/MSD, Gilead, Pfizer, Astellas Pharma, Basilea, Deutsches Zentrum für Infektionsforschung, and Bundesministerium für Bildung und Forschung.

\section{Author details}

'Service des Maladies Infectieuses, Hôpitaux Universitaires de Genève, Rue Gabrielle-Perret-Gentil 4, Geneva, Switzerland. ${ }^{2}$ Servicio de Enfermedades Infecciosas, Hospital Clínic de Barcelona-IDIBAPS, Universitat de Barcelona, FungiCLINIC Research group (AGAUR), Barcelona, Spain. ${ }^{3}$ Infectious Diseases Service, Department of Medicine, Lausanne University Hospital, 1011 Lausanne, Switzerland. ${ }^{4}$ Department of Laboratories, Institute of Microbiology, Lausanne University Hospital, Lausanne, Switzerland. ${ }^{5}$ Department of Anaesthesiology, Heidelberg University Hospital, Im Neuenheimer Feld 110, Heidelberg, Germany. ${ }^{6}$ VII Department of Infectious Disease and Immunology, Hospital D. Cotugno, Naples, Italy. ${ }^{7}$ CLSE-Liver Transplant Unit, Hospital A. Cardarelli, Naples, Italy. ${ }^{8}$ Medical Department II, Hematology and Oncology, University Hospital of Frankfurt, Frankfurt, Germany. ${ }^{9}$ Department I for Internal Medicine, University Hospital of Cologne, Cologne, Germany. ${ }^{10}$ German Centre for Infection Research, partner site Bonn-Cologne, University of Cologne, Cologne, Germany.

\section{Received: 6 January 2020 Accepted: 4 March 2021}

\section{Published online: 24 March 2021}

\section{References}

1. Neofytos D, Chatzis O, Nasioudis D, Boely Janke E, Doco Lecompte T, Garzoni C, et al. Epidemiology, risk factors and outcomes of invasive aspergillosis in solid organ transplant recipients in the Swiss transplant cohort study. Transpl Infect Dis. 2018;20(4):e12898.

2. Neofytos D, Fishman JA, Horn D, Anaissie E, Chang CH, Olyaei A, et al. Epidemiology and outcome of invasive fungal infections in solid organ transplant recipients. Transpl Infect Dis. 2010;12(3):220-9.

3. Pappas PG, Alexander BD, Andes DR, Hadley S, Kauffman CA, Freifeld A, et al. Invasive fungal infections among organ transplant recipients: results of the transplant-associated infection surveillance network (TRANSNET). Clin Infect Dis. 2010;50(8):1101-11.

4. Farmakiotis D, Kontoyiannis DP. Emerging issues with diagnosis and management of fungal infections in solid organ transplant recipients. Am J Transplant. 2015;15(5):1141-7.

5. Singh N, Husain S. Aspergillosis in solid organ transplantation. Am J Transplant. 2013;13(Suppl 4):228-41.

6. Zhou W, Li H, Zhang Y, Huang M, He Q, Li P, et al. Diagnostic value of galactomannan antigen test in serum and bronchoalveolar lavage fluid samples from patients with nonneutropenic invasive pulmonary aspergillosis. J Clin Microbiol. 2017;55(7):2153-61.

7. Hasseine L, Cassaing S, Robert-Gangneux F, Fillaux J, Marty P, Gangneux JP, et al. High negative predictive value diagnostic strategies for the reevaluation of early antifungal treatment: a multicenter prospective trial in patients at risk for invasive fungal infections. J Inf Secur. 2015;71(2):258-65.

8. Küpeli E, Ulubay G, Akkurt SB, Eyüboğlu FO, Sezgin A. Invasive pulmonary aspergillosis in heart transplant recipients. Exp Clin Transplant. 2015;13(Suppl 1): 356-60.

9. Munoz P, Ceron I, Valerio M, Palomo J, Villa A, Eworo A, et al. Invasive aspergillosis among heart transplant recipients: a 24-year perspective. J Heart Lung Transplant. 2014;33(3):278-88.

10. Neoh CF, Snell Gl, Kotsimbos T, Levvey B, Morrissey CO, Slavin MA, et al. Antifungal prophylaxis in lung transplantation--a world-wide survey. Am J Transplant. 2011;11(2):361-6.

11. Lamoth F, Chung SJ, Damonti L, Alexander BD. Changing epidemiology of invasive mold infections in patients receiving azole prophylaxis. Clin Infect Dis. 2017;64(11):1619-21.

12. Winston DJ, Limaye AP, Pelletier S, Safdar N, Morris MI, Meneses K, et al. Randomized, double-blind trial of anidulafungin versus fluconazole for prophylaxis of invasive fungal infections in high-risk liver transplant recipients. Am J Transplant. 2014;14(12):2758-64.

13. Herbrecht R, Bories P, Moulin JC, Ledoux MP, Letscher-Bru V. Risk stratification for invasive aspergillosis in immunocompromised patients. Ann N Y Acad Sci. 2012;1272:23-30.

14. Patterson TF, Thompson GR 3rd, Denning DW, Fishman JA, Hadley S, Herbrecht $R$, et al. Practice guidelines for the diagnosis and management of aspergillosis: 2016 update by the Infectious Diseases Society of America. Clin Infect Dis. 2016;63(4):e1-e60.

15. Ullmann AJ, Aguado JM, Arikan-Akdagli S, Denning DW, Groll AH, Lagrou K, et al. Diagnosis and management of Aspergillus diseases: executive summary of the 2017 ESCMID-ECMM-ERS guideline. Clin Microbiol Infect. 2018;24(Suppl 1):e1-e38.

16. Cornely OA, Alastruey-Izquierdo A, Arenz D, Chen SCA, Dannaoui E, Hochhegger B, et al. Global guideline for the diagnosis and management of mucormycosis: an initiative of the European Confederation of Medical Mycology in cooperation with the mycoses study group education and research consortium. Lancet Infect Dis. 2019;19(12):e405-21.

17. Schauwvlieghe A, Rijnders BJA, Philips N, Verwijs R, Vanderbeke L, Van Tienen C, et al. Invasive aspergillosis in patients admitted to the intensive care unit with severe influenza: a retrospective cohort study. Lancet Respir Med. 2018;6(10):782-92.

18. Vanderbeke L, Spriet I, Breynaert C, Rijnders BJA, Verweij PE, Wauters J. Invasive pulmonary aspergillosis complicating severe influenza: epidemiology, diagnosis and treatment. Curr Opin Infect Dis. 2018;31 (6):471-80.

19. Cavayas YA, Yusuff $H$, Porter R. Fungal infections in adult patients on extracorporeal life support. Crit Care. 2018;22(1):98.

20. Muñoz P, Valerio M, Palomo J, Giannella M, Yanez JF, Desco M, et al. Targeted antifungal prophylaxis in heart transplant recipients. Transplantation. 2013;96(7):664-9.

21. Lopez-Medrano F, Silva JT, Fernandez-Ruiz M, Carver PL, van Delden C, Merino $E$, et al. Risk factors associated with early invasive pulmonary aspergillosis in kidney transplant recipients: results from a multinational matched case-control study. Am J Transplant. 2016;16(7):2148-57.

22. Rosenhagen M, Feldhues R, Schmidt J, Hoppe-Tichy T, Geiss HK. A risk profile for invasive aspergillosis in liver transplant recipients. Infection. 2009;37(4):313-9.

23. Saliba F, Delvart V, Ichai $P$, Kassis N, Botterel F, Mihaila L, et al. Fungal infections after liver transplantation: outcomes and risk factors revisited in the MELD era. Clin Transpl. 2013;27(4):E454-61.

24. Gavaldà J, Len O, San Juan R, Aguado JM, Fortun J, Lumbreras C, et al. Risk factors for invasive aspergillosis in solid-organ transplant recipients: a casecontrol study. Clin Infect Dis. 2005;41(1):52-9. 
25. Husain S, Camargo JF. Invasive aspergillosis in solid organ transplant recipients: Guidelines from the American Society of Transplantation Infectious Diseases community of practice. Clin Transpl. 2019;33(9):e13544.

26. Aguilar CA, Hamandi B, Fegbeutel C, Silveira FP, Verschuuren EA, Ussetti P, et al. Clinical risk factors for invasive aspergillosis in lung transplant recipients: results of an international cohort study. J Heart Lung Transplant. 2018;37(10):1226-34

27. Pfeiffer CD, Fine JP, Safdar N. Diagnosis of invasive aspergillosis using a galactomannan assay: a meta-analysis. Clin Infect Dis. 2006;42(10):1417-27.

28. Husain S, Sole A, Alexander BD, Aslam S, Avery R, Benden C, et al. The 2015 International Society for Heart and Lung Transplantation guidelines for the management of fungal infections in mechanical circulatory support and cardiothoracic organ transplant recipients: executive summary. J Heart Lung Transplant. 2016;35(3):261-82.

29. Kahn FW, Jones JM, England DM. The role of bronchoalveolar lavage in the diagnosis of invasive pulmonary aspergillosis. Am J Clin Pathol. 1986;86(4): 518-23.

30. Kontoyiannis DP, Wessel VC, Bodey GP, Rolston KV. Zygomycosis in the 1990s in a tertiary-care cancer center. Clin Infect Dis. 2000;30(6):851-6.

31. Levy H, Horak DA, Tegtmeier BR, Yokota SB, Forman SJ. The value of bronchoalveolar lavage and bronchial washings in the diagnosis of invasive pulmonary aspergillosis. Respir Med. 1992;86(3):243-8.

32. McWhinney PH, Kibbler CC, Hamon MD, Smith OP, Gandhi L, Berger LA, et al. Progress in the diagnosis and management of aspergillosis in bone marrow transplantation: 13 years' experience. Clin Infect Dis. 1993;17(3):397-404.

33. Reichenberger F, Habicht J, Matt P, Frei R, Soler M, Bolliger CT, et al. Diagnostic yield of bronchoscopy in histologically proven invasive pulmonary aspergillosis. Bone Marrow Transplant. 1999;24(11):1195-9.

34. Schelenz S, Barnes RA, Barton RC, Cleverley JR, Lucas SB, Kibbler CC, et al. British Society for Medical Mycology best practice recommendations for the diagnosis of serious fungal diseases. Lancet Infect Dis. 2015;15(4):461-74.

35. Young RC, Bennett JE, Vogel CL, Carbone PP, DeVita VT. Aspergillosis. The spectrum of the disease in 98 patients. Medicine (Baltimore). 1970;49(2):147-73.

36. Lamoth F, Calandra T. Early diagnosis of invasive mould infections and disease. J Antimicrob Chemother. 2017;72(suppl 1):i19-28.

37. Lass-Florl C. How to make a fast diagnosis in invasive aspergillosis. Med Mycol. 2019;57(suppl 2):S155-s60.

38. Munoz P, Alcala L, Sanchez Conde M, Palomo J, Yanez J, Pelaez T, et al. The isolation of Aspergillus fumigatus from respiratory tract specimens in heart transplant recipients is highly predictive of invasive aspergillosis. Transplantation. 2003;75(3):326-9.

39. Buchheidt D, Reinwald M, Hoenigl M, Hofmann W-K, Spiess B, Boch T. The evolving landscape of new diagnostic tests for invasive aspergillosis in hematology patients: strengths and weaknesses. Curr Opin Infect Dis. 2017; 30(6):539-44.

40. Hoyo I, Sanclemente G, de la Bellacasa JP, Cofan F, Ricart MJ, Cardona M, et al. Epidemiology, clinical characteristics, and outcome of invasive aspergillosis in renal transplant patients. Transpl Infect Dis. 2014;16(6):951-7.

41. Kwak EJ, Husain S, Obman A, Meinke L, Stout J, Kusne S, et al. Efficacy of galactomannan antigen in the Platelia Aspergillus enzyme immunoassay for diagnosis of invasive aspergillosis in liver transplant recipients. J Clin Microbiol. 2004;42(1):435-8.

42. Singh $N$, Winston DJ, Limaye AP, Pelletier S, Safdar N, Morris Ml, et al. Performance characteristics of Galactomannan and beta-d-Glucan in highrisk liver transplant recipients. Transplantation. 2015:99(12):2543-50.

43. Akamatsu N, Sugawara Y, Kaneko J, Tamura S, Makuuchi M. Preemptive treatment of fungal infection based on plasma $(1 \rightarrow 3) \beta$-D-glucan levels after liver transplantation. Infection. 2007;35(5):346-51.

44. Alexander BD, Smith PB, Davis RD, Perfect JR, Reller LB. The (1,3)\{beta\}-Dglucan test as an aid to early diagnosis of invasive fungal infections following lung transplantation. J Clin Microbiol. 2010;48(11):4083-8.

45. Boch T, Buchheidt D, Spiess B, Miethke T, Hofmann WK, Reinwald M. Direct comparison of galactomannan performance in concurrent serum and bronchoalveolar lavage samples in immunocompromised patients at risk for invasive pulmonary aspergillosis. Mycoses. 2016;59(2):80-5.

46. Giacobbe DR, Del Bono V, Viscoli C, Mikulska M. Use of 1,3-beta-D-glucan in invasive fungal diseases in hematology patients. Expert Rev Anti-Infect Ther. 2017:15(12):1101-12.

47. Koo S, Bryar Julie M, Page John H, Baden Lindsey R, Marty FM. Diagnostic performance of the (1->3) beta-D-Glucan assay for invasive fungal disease. Clin Infect Dis. 2009;49(11):1650-9.
48. Marty FM, Koo S. Role of (1-->3)-beta-D-glucan in the diagnosis of invasive aspergillosis. Med Mycol. 2009;47(Suppl 1):S233-40.

49. Pazos C, Ponton J, Del Palacio A. Contribution of (1->3)-beta-D-glucan chromogenic assay to diagnosis and therapeutic monitoring of invasive aspergillosis in neutropenic adult patients: a comparison with serial screening for circulating galactomannan. J Clin Microbiol. 2005;43(1):299-305.

50. Levesque E, Rizk F, Noorah Z, Ait-Ammar N, Cordonnier-Jourdin C, El Anbassi S, et al. Detection of (1,3)-beta-d-Glucan for the Diagnosis of Invasive Fungal Infection in Liver Transplant Recipients. Int J Mol Sci. 2017;18(4).

51. Imbert S, Gauthier L, Joly I, Brossas JY, Uzunov M, Touafek F, et al. Aspergillus PCR in serum for the diagnosis, follow-up and prognosis of invasive aspergillosis in neutropenic and nonneutropenic patients. Clin Microbiol Infect. 2016;22(6):562 e1-8.

52. Imbert S, Gauthier L, Palous M, Joly I, Gay F, Brun S, et al. Performance of an Aspergillus fumigatus real-time PCR assay using serum for the diagnosis of invasive aspergillosis in neutropenic and non-neutropenic patients. Mycoses. 2015;58(Suppl. 4):44.

53. Imbert S, Meyer I, Palous M, Brossas JY, Uzunov M, Touafek F, et al. Aspergillus PCR in bronchoalveolar lavage fluid for the diagnosis and prognosis of aspergillosis in patients with hematological and nonhematological conditions. Front Microbiol. 2018;9:1877.

54. Hamprecht A, Buchheidt D, Vehreschild JJ, Cornely OA, Spiess B, Plum G, et al. Azole-resistant invasive aspergillosis in a patient with acute myeloid leukaemia in Germany. Euro Surveill. 2012;17(36):20262.

55. Steinmann J, Hamprecht A, Vehreschild MJ, Cornely OA, Buchheidt D, Spiess $B$, et al. Emergence of azole-resistant invasive aspergillosis in HSCT recipients in Germany. J Antimicrob Chemother. 2015;70(5):1522-6.

56. van Paassen J, Russcher A, In't Veld van Wingerden AW, Verweij PE, Kuijper EJ. Emerging aspergillosis by azole-resistant Aspergillus fumigatus at an intensive care unit in the Netherlands, 2010 to 2013. Euro Surveill. 2016; 21(30):1-9.

57. Lamoth F. Aspergillus fumigatus-related species in clinical practice. Front Microbiol. 2016;7:683.

58. Seroy J, Antiporta P, Grim SA, Proia LA, Singh K, Clark NM. Aspergillus calidoustus case series and review of the literature. Transpl Infect Dis. 2017; 19(5):e12755.

59. Egli A, Fuller J, Humar A, Lien D, Weinkauf J, Nador R, et al. Emergence of Aspergillus calidoustus infection in the era of posttransplantation azole prophylaxis. Transplantation. 2012;94(4):403-10.

60. Vahedi Shahandashti R, Lass-Flörl C. Antifungal resistance in Aspergillus terreus: a current scenario. Fungal Genet Biol. 2019;131:103247.

61. Rivero-Menendez O, Soto-Debran JC, Medina N, Lucio J, Mellado E, Alastruey-Izquierdo A. Molecular identification, antifungal susceptibility testing, and mechanisms of azole resistance in Aspergillus species received within a surveillance program on antifungal resistance in Spain. Antimicrob Agents Chemother. 2019;63(9):e00865-19.

62. Choi MJ, Won EJ, Joo MY, Park YJ, Kim SH, Shin MG, et al. Microsatellite typing and resistance mechanism analysis of Voriconazole-resistant Aspergillus flavus isolates in south Korean hospitals. Antimicrob Agents Chemother. 2019;63(2):e01610-8.

63. White PL, Posso RB, Barnes RA. Analytical and clinical evaluation of the PathoNostics AsperGenius assay for detection of invasive aspergillosis and resistance to azole antifungal drugs directly from plasma samples. J Clin Microbiol. 2017;55(8):2356-66.

64. Chong GM, van der Beek MT, von dem Borne PA, Boelens J, Steel E, Kampinga GA, et al. PCR-based detection of Aspergillus fumigatus Cyp51A mutations on bronchoalveolar lavage: a multicentre validation of the AsperGenius assay(R) in 201 patients with haematological disease suspected for invasive aspergillosis. J Antimicrob Chemother. 2016;71(12):3528-35.

65. Wang Q, Kontoyiannis DP, Li R, Chen W, Bu D, Liu W. A novel broad allelespecific TaqMan Real-Time PCR method to detect triazole-resistant strains of Aspergillus fumigatus, even with a very low percentage of triazole-resistant cells mixed with triazole-susceptible cells. J Clin Microbiol. 2019;57(9):e00604-19.

66. Imbert S, Normand AC, Gabriel F, Bonnal C, Lachaud L, Costa D, et al. In vitro antifungal susceptibility testing of cryptic species of Aspergillus: a multicentre study. Amsterdam: 29th ECCMID Congress; 2019.

67. Monteiro C, Pinheiro D, Maia M, Faria MA, Lameiras C, Pinto E. Aspergillus species collected from environmental air samples in Portugal-molecular identification, antifungal susceptibility and sequencing of cyp51A gene on A. fumigatus sensu stricto itraconazole resistant. J Appl Microbiol. 2019; 126(4):1140-8. 
68. Sanguinetti M, Posteraro B. Susceptibility testing of fungi to antifungal drugs. J Fungi (Basel). 2018;4(3):1-16.

69. Thornton CR. Development of an immunochromatographic lateral-flow device for rapid serodiagnosis of invasive aspergillosis. Clin Vaccine Immunol. 2008;15(7):1095-105.

70. Hoenigl M, Koidl C, Duettmann W, Seeber K, Wagner J, Buzina W, et al. Bronchoalveolar lavage lateral-flow device test for invasive pulmonary aspergillosis diagnosis in haematological malignancy and solid organ transplant patients. J Inf Secur. 2012;65(6):588-91.

71. Stucky Hunter E, Richardson MD, Denning DW. Evaluation of LD bio Aspergillus ICT lateral flow assay for IgG and IgM antibody detection in chronic pulmonary aspergillosis. J Clin Microbiol. 2019.

72. Johnson GL, Sarker SJ, Nannini F, Ferrini A, Taylor E, Lass-Florl C, et al. Aspergillusspecific lateral-flow device and real-time PCR testing of bronchoalveolar lavage fluid: a combination biomarker approach for clinical diagnosis of invasive pulmonary aspergillosis. J Clin Microbiol. 2015;53(7):2103-8.

73. Miceli MH, Goggins MI, Chander P, Sekaran AK, Kizy AE, Samuel L, et al. Performance of lateral flow device and galactomannan for the detection of Aspergillus species in bronchoalveolar fluid of patients at risk for invasive pulmonary aspergillosis. Mycoses. 2015;58(6):368-74.

74. Eigl S, Prattes J, Reinwald M, Thornton CR, Reischies F, Spiess B, et al. Influence of mould-active antifungal treatment on the performance of the Aspergillus-specific bronchoalveolar lavage fluid lateral-flow device test. Int J Antimicrob Agents. 2015;46(4):401-5.

75. Kovanda LL, Desai AV, Hope WW. Prognostic value of galactomannan: current evidence for monitoring response to antifungal therapy in patients with invasive aspergillosis. J Pharmacokinet Pharmacodyn. 2017;44(2):143-51.

76. Chai L, Netea MG, Teerenstra S, Earnest A, Vonk AG, Schlamm HT, et al. Early proinflammatory cytokines and C-reactive protein trends as predictors of outcome in invasive aspergillosis. J Infect Dis. 2010;202(9):1454-62.

77. Krel M, Petraitis V, Petraitiene R, Jain MR, Zhao Y, Li H, et al. Host biomarkers of invasive pulmonary aspergillosis to monitor therapeutic response. Antimicrob Agents Chemother. 2014;58(6):3373-8.

78. Zhao Y, Nagasaki Y, Paderu P, Sugrue MW, Leather HL, Wingard JR, et al. Applying host disease status biomarkers to therapeutic response monitoring in invasive aspergillosis patients. Med Mycol. 2019;57(1):38-44.

79. Heinz WJ, Vehreschild JJ, Buchheidt D. Diagnostic work up to assess early response indicators in invasive pulmonary aspergillosis in adult patients with haematologic malignancies. Mycoses. 2019;62(6):486-93.

80. Park YS, Seo JB, Lee YK, Do KH, Lee JS, Song JW, et al. Radiological and clinical findings of pulmonary aspergillosis following solid organ transplant. Clin Radiol. 2008;63(6):673-80.

81. Qin J, Fang Y, Dong Y, Zhu K, Wu B, An Y, et al. Radiological and clinical findings of 25 patients with invasive pulmonary aspergillosis: retrospective analysis of 2150 liver transplantation cases. Br J Radiol. 2012;85(1016):e429-35.

82. Park SY, Lim C, Lee S-O, Choi S-H, Kim YS, Woo JH, et al. Computed tomography findings in invasive pulmonary aspergillosis in non-neutropenic transplant recipients and neutropenic patients, and their prognostic value. J Inf Secur. 2011;63(6):447-56.

83. De Pauw B, Walsh TJ, Donnelly JP, Stevens DA, Edwards JE, Calandra T, et al. Revised definitions of invasive fungal disease from the European Organization for Research and Treatment of Cancer/invasive fungal infections cooperative group and the National Institute of Allergy and Infectious Diseases mycoses study group (EORTC/MSG) consensus group. Clin Infect Dis. 2008;46(12):1813-21.

84. Donnelly JP, Chen SC, Kauffman CA, Steinbach WJ, Baddley JW, Verweij PE, et al. Revision and Update of the Consensus Definitions of Invasive Fungal Disease From the European Organization for Research and Treatment of Cancer and the Mycoses Study Group Education and Research Consortium. Clin Infect Dis. 2020;71(6):1367-76.

85. Lopez-Medrano F, Fernandez-Ruiz M, Silva JT, Carver PL, van Delden C, Merino $E$, et al. Clinical presentation and determinants of mortality of invasive pulmonary aspergillosis in kidney transplant recipients: a multinational cohort study. Am J Transplant. 2016;16(11):3220-34.

86. Henzler C, Henzler T, Buchheidt D, Nance JW, Weis CA, Vogelmann R, et al. Diagnostic performance of contrast enhanced pulmonary computed tomography angiography for the detection of angioinvasive pulmonary aspergillosis in immunocompromised patients. Sci Rep. 2017;7(1):4483.

87. Stanzani M, Battista G, Sassi C, Lewis RE, Tolomelli G, Clissa C, et al. Computed tomographic pulmonary angiography for diagnosis of invasive mold diseases in patients with hematological malignancies. Clin Infect Dis. 2012;54(5):610-6.
88. Stanzani M, Sassi C, Lewis RE, Tolomelli G, Bazzocchi A, Cavo M, et al. High resolution computed tomography angiography improves the radiographic diagnosis of invasive mold disease in patients with hematological malignancies. Clin Infect Dis. 2015;60(11):1603-10.

89. Maertens JA, Raad II, Marr KA, Patterson TF, Kontoyiannis DP, Cornely OA, et al. Isavuconazole versus voriconazole for primary treatment of invasive mould disease caused by Aspergillus and other filamentous fungi (SECURE): a phase 3, randomised-controlled, non-inferiority trial. Lancet. 2016; 387(10020):760-9.

90. Kieu V, Jhangiani K, Dadwal S, Nakamura R, Pon D. Effect of Isavuconazole on Tacrolimus and Sirolimus Serum Concentrations in Allogeneic Hematopoietic Stem Cell Transplant Patients: A Drug-Drug Interaction Study. Transpl Infect Dis. 2018;21(1):e13007.

91. Kovanda LL, Kolamunnage-Dona R, Neely M, Maertens J, Lee M, Hope WW. Pharmacodynamics of isavuconazole for invasive mold disease: role of galactomannan for real-time monitoring of therapeutic response. Clin Infect Dis. 2017;64(11):1557-63.

92. Lepak AJ, Andes DR. Antifungal pharmacokinetics and pharmacodynamics. Cold Spring Harb Perspect Med. 2014;5(5):a019653.

93. Theuretzbacher U. Pharmacokinetic and pharmacodynamic issues for antimicrobial therapy in patients with cancer. Clin Infect Dis. 2012;54(12): $1785-92$.

94. Wurthwein G, Young C, Lanvers-Kaminsky C, Hempel G, Trame MN, Schwerdtfeger $R$, et al. Population pharmacokinetics of liposomal amphotericin $B$ and caspofungin in allogeneic hematopoietic stem cell recipients. Antimicrob Agents Chemother. 2012;56(1):536-43.

95. Bellmann R. Pharmacodynamics and pharmacokinetics of antifungals for treatment of invasive aspergillosis. Curr Pharm Des. 2013;19(20):3629-47.

96. Dodds-Ashley E. Management of drug and food interactions with azole antifungal agents in transplant recipients. Pharmacotherapy. 2010;30(8):842-54.

97. Hamill RJ. Amphotericin B formulations: a comparative review of efficacy and toxicity. Drugs. 2013;73(9):919-34.

98. Lempers VJ, Martial LC, Schreuder MF, Blijlevens NM, Burger DM, Aarnoutse $R E$, et al. Drug-interactions of azole antifungals with selected immunosuppressants in transplant patients: strategies for optimal management in clinical practice. Curr Opin Pharmacol. 2015;24:38-44.

99. Cornely OA, Arikan-Akdagli S, Dannaoui E, Groll AH, Lagrou K, Chakrabarti A, et al. ESCMID and ECMM joint clinical guidelines for the diagnosis and management of mucormycosis 2013. Clin Microbiol Infect. 2014;20(Suppl. 3): $5-26$.

100. Garcia-Vidal C. Current therapeutic options in invasive mycosis and potential therapeutic role of isavuconazole. Rev Iberoam Micol. 2018;35(4):192-7.

101. Garcia-Vidal C, Alastruey-Izquierdo A, Aguilar-Guisado M, Carratala J, Castro C, Fernandez-Ruiz M, et al. Executive summary of clinical practice guideline for the management of invasive diseases caused by Aspergillus: 2018 Update by the GEMICOMED-SEIMC/REIPI. Enferm Infecc Microbiol Clin. 2019: 37(8):535-41.

102. Sipsas NV, Gamaletsou MN, Anastasopoulou A, Kontoyiannis DP. Therapy of Mucormycosis. J Fungi (Basel). 2018;4(3):90-107.

103. Tortorano AM, Richardson M, Roilides E, van Diepeningen A, Caira M, Munoz $P$, et al. ESCMID and ECMM joint guidelines on diagnosis and management of hyalohyphomycosis: Fusarium spp., Scedosporium spp. and others. Clin Microbiol Infect. 2014:20(Suppl. 3):27-46.

104. Groll AH, Townsend R, Desai A, Azie N, Jones M, Engelhardt M, et al. Drugdrug interactions between triazole antifungal agents used to treat invasive aspergillosis and immunosuppressants metabolized by cytochrome P450 3A4. Transpl Infect Dis. 2017;19(5)1-11.

105. Stott KE, Hope WW. Therapeutic drug monitoring for invasive mould infections and disease: pharmacokinetic and pharmacodynamic considerations. J Antimicrob Chemother. 2017;72(suppl_1):i12-i8.

106. Luong ML, Al-Dabbagh M, Groll AH, Racil Z, Nannya Y, Mitsani D, et al. Utility of voriconazole therapeutic drug monitoring: a meta-analysis. J Antimicrob Chemother. 2016;71(7):1786-99.

107. Park WB, Kim NH, Kim KH, Lee SH, Nam WS, Yoon SH, et al. The effect of therapeutic drug monitoring on safety and efficacy of voriconazole in invasive fungal infections: a randomized controlled trial. Clin Infect Dis. 2012;55(8):1080-7.

108. Guinea J, Escribano P, Marcos-Zambrano LJ, Peláez T, Kestler M, Muñoz P, et al. Therapeutic drug monitoring of voriconazole helps to decrease the percentage of patients with off-target trough serum levels. Med Mycol. 2016;54(4):353-60. 
109. Neofytos D, Ostrander D, Shoham S, Laverdiere M, Hiemenz J, Nguyen H, et al. Voriconazole therapeutic drug monitoring: results of a prematurely discontinued randomized multicenter trial. Transpl Infect Dis. 2015;17(6):831-7.

110. Falci DR, Pasqualotto AC. Profile of isavuconazole and its potential in the treatment of severe invasive fungal infections. Infect Drug Resist. 2013;6:163-74.

111. Wu X, Clancy CJ, Rivosecchi RM, Zhao W, Shields RK, Marini RV, et al. Pharmacokinetics of Intravenous Isavuconazole in Solid-Organ Transplant Recipients. Antimicrob Agents Chemother. 2018;62(12):1-13.

112. Wu X, Venkataramanan R, Rivosecchi RM, Tang C, Marini RV, Shields RK, et al. Population pharmacokinetics of intravenous Isavuconazole in solid-organ transplant recipients. Antimicrob Agents Chemother. 2020;64(2):e01728-19.

113. Baddley JW, Andes DR, Marr KA, Kontoyiannis DP, Alexander BD, Kauffman CA, et al. Factors associated with mortality in transplant patients with invasive aspergillosis. Clin Infect Dis. 2010;50(12):1559-67.

114. Steinbach WJ, Marr KA, Anaissie EJ, Azie N, Quan SP, Meier-Kriesche HU, et al. Clinical epidemiology of 960 patients with invasive aspergillosis from the PATH Alliance registry. J Inf Secur. 2012;65(5):453-64.

115. Marr KA, Schlamm HT, Herbrecht R, Rottinghaus ST, Bow EJ, Cornely OA, et al. Combination antifungal therapy for invasive aspergillosis: a randomized trial. Ann Intern Med. 2015;162(2):81-9.

116. du Pre S, Beckmann N, Almeida MC, Sibley GEM, Law D, Brand AC, et al. Effect of the novel antifungal drug F901318 (Olorofim) on growth and viability of Aspergillus fumigatus. Antimicrob Agents Chemother. 2018;62(8): $1-11$.

117. Lackner M, Birch M, Naschberger V, Grassle D, Beckmann N, Warn P, et al. Dihydroorotate dehydrogenase inhibitor olorofim exhibits promising activity against all clinically relevant species within Aspergillus section Terrei. J Antimicrob Chemother. 2018;73(11):3068-73.

118. Davis MR, Donnelley MA, Thompson GR. Ibrexafungerp: A novel oral glucan synthase inhibitor. Med Mycol. 2019. https://doi.org/10.1093/mmy/myz083.

119. Ullmann AJ, Lipton JH, Vesole DH, Chandrasekar P, Langston A, Tarantolo $\mathrm{SR}$, et al. Posaconazole or fluconazole for prophylaxis in severe graft-versushost disease. N Engl J Med. 2007;356(4):335-47.

120. Peghin M, Monforte V, Martin-Gomez MT, Ruiz-Camps I, Berastegui C, Saez B, et al. 10 years of prophylaxis with nebulized liposomal amphotericin B and the changing epidemiology of Aspergillus spp. infection in lung transplantation. Transpl Int. 2016;29(1):51-62.

121. Perrella A, Esposito C, Amato G, Perrella O, Migliaccio C, Pisaniello D, et al. Antifungal prophylaxis with liposomal amphotericin $B$ and caspofungin in high-risk patients after liver transplantation: impact on fungal infections and immune system. Infect Dis. 2016;48(2):161-6.

122. Perrella A, Esposito C, Pisaniello D, D'Alessio L, Perrella O, Marcos A, et al. Role of liposomal amphotericin B prophylaxis after liver transplantation compared with fluconazole for high-risk patients. Impact on infections and mortality within one year. Transplant Proc. 2012;44(7):1977-81.

123. Baker AW, Maziarz EK, Arnold CJ, Johnson MD, Workman AD, Reynolds JM, et al. Invasive fungal infection after lung transplantation: epidemiology in the setting of antifungal prophylaxis. Clin Infect Dis. 2020;70(1):30-9.

124. Auberger J, Lass-Florl C, Aigner M, Clausen J, Gastl G, Nachbaur D. Invasive fungal breakthrough infections, fungal colonization and emergence of resistant strains in high-risk patients receiving antifungal prophylaxis with posaconazole: real-life data from a single-Centre institutional retrospective observational study. J Antimicrob Chemother. 2012;67(9):2268-73.

125. Lerolle N, Raffoux E, Socie G, Touratier S, Sauvageon H, Porcher R, et al. Breakthrough invasive fungal disease in patients receiving posaconazole primary prophylaxis: a 4-year study. Clin Microbiol Infect. 2014;20(11):0952-9.

126. Biehl LM, Vehreschild JJ, Liss B, Franke B, Markiefka B, Persigehl T, et al. A cohort study on breakthrough invasive fungal infections in high-risk patients receiving antifungal prophylaxis. J Antimicrob Chemother. 2016;71(9):2634-41.

127. Cornely OA, Maertens J, Bresnik M, Ebrahimi R, Ullmann AJ, Bouza E, et al. Liposomal amphotericin B as initial therapy for invasive mold infection: a randomized trial comparing a high-loading dose regimen with standard dosing (AmBiLoad trial). Clin Infect Dis. 2007;44(10):1289-97.

128. Corzo-Leon DE, Satlin MJ, Soave R, Shore TB, Schuetz AN, Jacobs SE, et al. Epidemiology and outcomes of invasive fungal infections in allogeneic haematopoietic stem cell transplant recipients in the era of antifungal prophylaxis: a single-Centre study with focus on emerging pathogens. Mycoses. 2015;58(6):325-36.

129. Rausch CR, DiPippo AJ, Bose P, Kontoyiannis DP. Breakthrough fungal infections in leukemia patients receiving isavuconazole. Clin Infect Dis. 2018; 67(10):1610-13.
130. Winston DJ, Bartoni K, Territo MC, Schiller GJ. Efficacy, safety, and breakthrough infections associated with standard long-term posaconazole antifungal prophylaxis in allogeneic stem cell transplantation recipients. Biol Blood Marrow Transplant. 2011;17(4):507-15.

131. Segal BH, Herbrecht R, Stevens DA, Ostrosky-Zeichner L, Sobel J, Viscoli C, et al. Defining responses to therapy and study outcomes in clinical trials of invasive fungal diseases: mycoses study group and European Organization for Research and Treatment of Cancer consensus criteria. Clin Infect Dis. 2008;47(5):674-83.

132. Caillot D, Couaillier JF, Bernard A, Casasnovas O, Denning DW, Mannone L, et al. Increasing volume and changing characteristics of invasive pulmonary aspergillosis on sequential thoracic computed tomography scans in patients with neutropenia. J Clin Oncol. 2001;19(1):253-9.

133. Caillot D, Latrabe V, Thiebaut A, Herbrecht R, De Botton S, Pigneux A, et al. Computer tomography in pulmonary invasive aspergillosis in hematological patients with neutropenia: an useful tool for diagnosis and assessment of outcome in clinical trials. Eur J Radiol. 2010;74(3):e172-5.

134. Lim C, Seo JB, Park SY, Hwang HJ, Lee HJ, Lee SO, et al. Analysis of initial and follow-up CT findings in patients with invasive pulmonary aspergillosis after solid organ transplantation. Clin Radiol. 2012;67(12):1179-86.

135. Lim MC, Tan CH, Cai J, Zheng J, Kow AWC. CT volumetry of the liver: where does it stand in clinical practice? Clin Radiol. 2014;69(9):887-95.

136. Vehreschild JJ, Heussel CP, Groll AH, Vehreschild M, Silling G, Wurthwein G, et al. Serial assessment of pulmonary lesion volume by computed tomography allows survival prediction in invasive pulmonary aspergillosis. Eur Radiol. 2017;27(8):3275-82.

137. Koo S, Bryar JM, Baden LR, Marty FM. Prognostic features of galactomannan antigenemia in galactomannan-positive invasive aspergillosis. J Clin Microbiol. 2010;48(4):1255-60.

138. Nouér SA, Nucci M, Kumar NS, Grazziutti M, Barlogie B, Anaissie E. Earlier response assessment in invasive aspergillosis based on the kinetics of serum Aspergillus galactomannan: proposal for a new definition. Clin Infect Dis. 2011;53(7):671-6.

139. Cho HJ, Jang MS, Hong SD, Chung SK, Kim HY, Dhong HJ. Prognostic factors for survival in patients with acute invasive fungal rhinosinusitis. Am J Rhinol Allergy. 2015;29(1):48-53.

140. Vandewoude K, Blot S, Benoit D, Depuydt P, Vogelaers D, Colardyn F. Invasive aspergillosis in critically ill patients: analysis of risk factors for acquisition and mortality. Acta Clin Belg. 2004;59(5):251-7.

141. Baddley JW. Clinical risk factors for invasive aspergillosis. Med Mycol. 2011; 49(Suppl 1):S7-S12.

142. Baddley JW, Stephens JM, Ji X, Gao X, Schlamm HT, Tarallo M. Aspergillosis in intensive care unit (ICU) patients: epidemiology and economic outcomes. BMC Infect Dis. 2013;13:29.

143. Bassetti M, Bouza E. Invasive mould infections in the ICU setting: complexities and solutions. J Antimicrob Chemother. 2017;72(suppl 1):i39-47.

144. Cornillet A, Camus C, Nimubona S, Gandemer V, Tattevin P, Belleguic C, et al. Comparison of epidemiological, clinical, and biological features of invasive aspergillosis in neutropenic and nonneutropenic patients: a 6-year survey. Clin Infect Dis. 2006;43(5):577-84.

145. Moreno G, Rodriguez A, Reyes LF, Gomez J, Sole-Violan J, Diaz E, et al. Corticosteroid treatment in critically ill patients with severe influenza pneumonia: a propensity score matching study. Intensive Care Med. 2018; 44(9):1470-82

146. Petrikkos G, Skiada A, Lortholary O, Roilides E, Walsh TJ, Kontoyiannis DP. Epidemiology and clinical manifestations of mucormycosis. Clin Infect Dis. 2012;54(suppl 1):S23-34.

147. Tejerina EE, Abril E, Padilla R, Rodriguez Ruiz C, Ballen A, Frutos-Vivar F, et al. Invasive aspergillosis in critically ill patients: An autopsy study. Mycoses. 2019;62(8):673-9.

148. Singh N, Husain S. Practice AIDCo. Invasive aspergillosis in solid organ transplant recipients. Am J Transplant. 2009;9:S180-S91.

149. Singh N, Pruett TL, Houston S, Munoz P, Cacciarelli TV, Wagener MM, et al. Invasive aspergillosis in the recipients of liver retransplantation. Liver Transpl. 2006;12(8):1205-9.

\section{Publisher's Note}

Springer Nature remains neutral with regard to jurisdictional claims in published maps and institutional affiliations. 